\title{
The Study of Images in Xu Zhimo's Poetry of Sayannala's 18 Poems and Farewell to Cambridge from the Perspective of Figure-Ground Theory in Cognitive Poetics
}

\author{
Feifei Zhao \\ Tiangong University, Tianjin, China \\ Email: 1263337361@qq.com
}

How to cite this paper: Zhao, F.F. (2021) The Study of Images in Xu Zhimo's Poetry of Sayannala's 18 Poems and Farewell to Cambridge from the Perspective of FigureGround Theory in Cognitive Poetics. Open Access Library Journal, 8: e7667. https://doi.org/10.4236/oalib.1107667

Received: June 21, 2021

Accepted: July 10, 2021

Published: July 13, 2021

Copyright () 2021 by author(s) and Open Access Library Inc.

This work is licensed under the Creative Commons Attribution International License (CC BY 4.0).

http://creativecommons.org/licenses/by/4.0/

\begin{abstract}
Figure-ground theory is one of the most important analytical tools in cognitive poetics. Based on the theory of figure-ground, this paper uses the classical love poems of Xu Zhimo, the representative of the Crescent School of poetry, as the Corpus, and analyzes them from three levels: vocabulary, syntax and textual emotion. The purpose of this paper is to explore the beauty of images in Xu Zhimo's poetry. The text is based on the emotions of the text, and the emotions expressed in the poem are constructed into images of the poem through figure-ground theory in cognitive poetics. Thus, the modern poetry is interpreted.
\end{abstract}

\section{Subject Areas \\ Cognitive Linguistics}

\section{Keywords}

Cognitive Poetics, Figure-Ground Theory, Vocabulary, Xu Zhimo's Poems, Textual Emotion

\section{Introduction}

Cognitive poetics emerged in the 1970s, originally proposed by Professor Reuven Tsur of Tel Aviv University in Israel, as a new interdisciplinary subject based on cognitive linguistics and literary studies. From the 1970s to the present, cognitive poetics abroad began to develop vigorously. Tsur has published a Theory of 
Cognitive poetry, Toward a Theory of Cognitive Poetics and Poetic Rhythm: Structure and Performance-An Empirical Study in Cognitive Poetics; the former points out that cognitive poetics is an interdisciplinary method of studying literature with the aid of cognitive tools, which aims to bridge the gap between human values and trivial styles [1]. The latter mainly analyzes the relationship between stress and rhyme from the perspective of gestalt perception, and concludes that the rhyme of poetry can only be perceived in recitation. At the same time, Stockwell thinks that cognitive poetics is about reading literature. Besides, he applies cognitive linguistics and psychology to literary text analysis, which is a way of thinking about literature. Cognitive poetics is not a theory of literary criticism, but a cognitive process that restricts literary response and poetic structure, providing theoretical cognitive basis for literary perception [2].

The Philosophical Foundation of Cognitive Linguistics is embodied philosophy, which holds that language and language use are based on human cognition and are a part of human cognitive ability. Language is not an autonomous cognitive function, and grammar is the result of conceptualization. With the rapid development of cognitive science and cognitive linguistics, literary studies have also begun to turn to cognitive poetics, which combines cognitive linguistics, cognitive psychology and literary criticism to interdisciplinary literary texts.

Cognitive poetics integrates context into its theoretical framework and analyzes text, context, environment, usage, knowledge and belief to understand literary value and significance. The study of cognitive poetics abroad involves the theoretical study of cognitive poetics, the methodology of cognitive poetics and the application of cognitive poetics to literary discourse. With the rise of cognitive poetics, the study of poetry based on philosophy or emotion has turned [3]. With the development of cognitive poetics in full swing abroad, Chinese literary studies have begun in the early 21st century from the perspectives of cognitive linguistics and cognitive psychology. Based on the figure-ground theory, this paper explicates the images in Xu Zhimo's classic love poems through three levels: lexical level, syntactic level and emotional level.

\section{Figure-Ground Theory}

The study of figure as background was first proposed by Danish psychologist Rubin about a century ago, which is called the distinction between figure and background. Talmy was the first to apply the figure-ground theory to linguistic studies. Cognitive poetics uses figure-ground theory to analyze literary texts, and holds that figure and ground are the basic features that should be paid attention to in literary texts research [4]. The reason why a figure is a figure rather than a background is that it usually has one or more of the following characteristics to make it stand out: the figure itself is a gestalt structure, with clearly discernible boundaries separating it from the background; The mobility of the figure is related to the relatively static background, the figure takes precedence over the background in time or space, the figure is a part of the background, but is sepa- 
rated from the background, or the figure is gradually separated from the background to become the figure; Graphics are more specific and appealing than other views or text; graphics are above or before the background. Generally speaking, the figure and the background in literature are relatively fixed, but also have the figure and the background continuously transformation process.

Stockwell, on the basis of previous studies, further proposed the dynamic figure-ground theory. Stockwell pointed out that the interaction between a figure and a background includes the following situations: 1) the figure occupies a prominent position to create a sense of three-dimensional, dynamic sense; 2) the figure moves over the background and becomes the focus of attention; 3) the figure and ground are transformed as the perspective changes [2].

With the development of the theory of figure-ground, scholars in China began to study it locally and put forward a lot of constructive ideas. At present, the study of figure-ground theory in China is mainly embodied in four levels: syntactic analysis, translation and research, interpretation of poetry and so on, the interpretation theory of these texts, teaching and discourse analysis. Among them, syntactic analysis and interpretation of poetry and other texts account for a major proportion.

\section{A Cognitive Interpretation of Xu Zhimo's Classical Love Poems}

Figure-ground theory has been proved to be effective in explaining such linguistic phenomena as syntactic diversity, sentence structure, the use of prepositions, the determination of time adverbials, and the emphasis mechanism of inversion [5]. Decomposing language structure into easy-to-understand figures or backgrounds can make our understanding and cognition more vivid. Based on the theory of figure and ground, and Xu Zhimo's classic love poems as the Corpus, this paper analyzes the process of figure-ground construction in terms of vocabulary, syntax and textual emotion, and reveals the beauty of poetic image in the cognitive framework.

\subsection{Lexical Level}

Talmy's figure-ground theory states that a figure is relatively mobile or conceptually movable and has a high degree of salience [4]. In the meantime, Stockwell points out: "In most literary texts, the context is the point of reference, the figure is the figure, and the context is the context" [2]. In Xu Zhimo's love poems, images are often the subject or object, forming the figures of the poems, and adjectives and other qualifying words are used to highlight the images and form the background of the poems.

Case 1

那河畔的金柳, 是夕阳中的新娘; 波光里的艳影, 在我的心头荡漾。

— 《再别康桥》

Analysis: In the poem, the Noun “金柳(Golden Willow)” is compared to “新 
娘(bride)” and “艳影(Gorgeous Shadow)” [6], which “荡漾(ripples)” in the author's heart. “金柳(Golden Willow)” is the focus of description in this section, and the focus turns into a figure. Compared with “金柳(Golden willow)”, “新娘 (bride)”, “艳影(Gorgeous Shadow)” and “荡漾(ripples)” revolve around “金柳 (Golden Willow)", which is the reference point and background for the description of “新娘(Golden willow)”, a known feature that describes an unknown aspect of a graph.

\section{Case 2}

寻梦? 撑一支长篙, 向青草更青处漫溯; 满载一船星辉, 在星辉斑斓里放 歌。

- 《再别康桥》

Analysis: In this section, the “寻梦(dream-seeking)" is the center, and the three verbs of “撑(punt)”, “漫溯(wander)” and “放歌(singing)” support the process of dream-seeking. It constructs the cognitive level of dream-seeking, the skeleton of detail, which becomes a figure through cognitive processing.

\section{Case 3}

我记得扶桑海上的朝阳, 黄金似的撒在扶桑的海上; 我记得扶桑海上的群 岛, 翡翠似的浮沤在扶桑的海上一一沙扬娜拉！

\section{— 《沙扬娜拉十八首》}

Analysis: In this stanza, the images “朝阳(The rising sun)” and “群岛 (islands)" are used as objects and subjects in the poem. “朝阳(The rising sun)” scattering on the sea, “群岛(islands)” floating in the sea, these scenes attract the reader's attention, highlighting the degree of high, built into the image of poetry. Applying figure-ground theory to the interpretation of poetry vocabulary can activate the process of the original image in the brain. Through the cognitive interpretation of the image of this poem, the pursuit of Love, freedom and beauty in the heart of the poet is constructed.

\subsection{Syntactic Level}

In terms of cognitive grammar, in a simple sentence where transitive verbs serve as predicates, the subject is the figure, the object is the ground, and the verb indicates the relationship between the two parts. The salient part of a sentence is usually the subject, so it naturally becomes the part that people pay more attention to, that is, the figure. Choose different parts of the subject, the result is a cognitive production of different graphics. According to the different cognitive salience, we can also put different sentence components in the salience position to play the role of emphasis, that is, the salience sentence components can be constructed as a figure.

First, the use of inversion. For example, in 《再别康桥》, the first verse of the poem “轻轻的我走了, 正如我轻轻的来” and the seventh verse “悄悄的我走了, 正如我悄悄的来” are both inverted sentences, constitutes an inversion order. In this cognitive perspective, adverbials “轻轻的(quietly)" and “悄悄的(quietly)” are placed at the beginning of a sentence to form a poem figure, which highlights 
the poet's feelings of being reluctant to leave but unable to do so.

Secondly, the use of compound sentences. In a compound sentence, the clause is the complement to the main clause, and the main clause is explained by extension or enhancement. Therefore, in a compound sentence, the main clause is the figure and the subordinate clause is the ground, and if the cognitive perspective changes, the image in the clause can also be constructed into a figure to achieve a prominent effect.

\section{Case 4}

趁航在轻涛间, 悠悠的, 我看见有一星星古式的渔舟, 想一群无忧的海鸟, 在黄昏的波光里息羽优游，沙扬娜拉！

\section{《沙扬娜拉十八首》}

Analysis: “我看见有一星星古式的渔舟” is the main sentence of this section. “像一群无忧的海鸟, 在黄昏的波光里息羽优游” constructs a clause as a modification of this section. The image “渔舟(fishing boat)" is the figure of the poem in this section, and the subordinate clause is the modification and supplement of the image, so it is the background of the poem. With the change of the poet's cognitive perspective, the image of Seabirds in the clause is transformed from background to figure. Like a group of carefree seabirds, swimming in the evening waves, the fishing boat gradually transitioned to seabirds, highlighting the scene of seabirds flying leisurely in the evening. Therefore, at this level of cognitive processing, seabirds are transformed into poetic images.

\section{Case 5}

那榆阴下的一潭, 不是清泉, 是天上虹。

\section{- 《再别康桥》}

Analysis: The application of “不是” and “是” in this compound sentence constitutes a turning point and a contrast, highlights the “谭(pool)” of poetic image, and constitutes a poetic figure. In the clause “天上虹(the rainbow in the sky)", the prominence of the poem moves from “一潭(one pool)" to “虹 (rainbow)", completing the transformation of cognitive perspective, and the figure turns into “虹(rainbow)".

Finally, it is the use of repeated sentences. Emphasize and highlight the subject by using repeated sentences.

\section{Case 6}

我爱慕她们体态的轻盈, 妩媚是天生, 妩媚是天生！我爱慕她们颜色的调 匀, 蝴蝶似的光艳, 蝴蝶似的轻盈——沙扬娜拉!

— 《沙扬娜拉十八首》

Analysis: The poet uses two sentences in succession, “妩媚是天生(charm is born)”, to accentuate their charm through repetition, and two “蝴蝶似的 (butterfly-like)" to accentuate their colors. Therefore, the modifiers “妩媚 (charm)” and “蝴蝶似的(butterfly-like)” become the focus of this section and construct the figures for this stanza. To sum up, the poet uses inverted sentence, compound sentence and repeated sentence to construct figure and background, and to highlight the beauty of poetic image. 


\subsection{The Emotional Level}

The picture depicted in the poem is dynamic. Through the change and movement of the focus, it can show the real and perceptible scene in all directions. From the cognitive point of view, the change of focus is the transformation between the cognitive figure and the background. The poet changes the feeling focus and creates different artistic conception to make the readers feel the feelings in the scene. Through a series of images, the poem highlights the poet's emotion and completes the deeper processing of cognition. In Xu Zhimo's love poems, images bear the poet's pursuit and longing for freedom and love. On this cognitive level, image is the carrier of emotion, which is transformed into the background of poetry, and emotion is the focus of poetry and is constructed into the figure of poetry.

For instance, 《月下待杜鹃不来》 expresses the poet's desire for ideal love. The poet chooses the image Cuckoo to refer to the person he likes, expressing the waiting for love. The Azalea carries the waiting for love, which becomes the background of the poem, while the waiting for love forms the figure of the poem. The whole poem revolves around this theme, so the theme conveyed by the title is constructed as a foregrounding content [1]. The images of the bridge, the moon and the boat in the poem bear the poet's inner waiting and express the poet's praise and pursuit of love. On the cognitive level of emotion, image is transformed into background and emotion is sublimated into figure.

Another example, the poem 《再别康桥》 expresses Xu Zhimo's love for Cambridge, his memories of his past life and his disconsolate and reluctant parting. The poem not only depicts the departure of Cambridge, but also reveals the poet's pursuit of freedom, love and beauty. Poetry takes image as the carrier, conveys the poet's emotion, completes the deeper processing, and highlights the cognitive process.

\section{Conclusions}

Cognitive poetics emphasizes how literary works achieve the desired effect through the reader's cognitive reaction from the reader's point of view. Figure-ground theory is an important idea in cognitive poetics, which is based on the concept of cognitive salience [3].

Based on the figure-ground theory, this paper analyzes Xu Zhimo's classic love poems from the Lexical, syntactic and textual levels. It is found that the theory of figure-ground can be applied not only to the study of classical poetry, but also to the analysis of modern poetry images, which provides a new perspective for the analysis of modern poetry. The domestic research pays more attention to take the classical poetry as the Corpus, and to the modern poetry analysis still has the broad development space. The future research can balance the interpretation of classical poetry and modern poetry, and promote the development of figure-ground theory.

Although many scholars at home and abroad have studied Xu Zhimo's poems, 
there are few studies that combine figure-ground theory with poetic images, and more of our scholars are needed to do so, which need more scholars to study.

\section{Conflicts of Interest}

The author declares no conflicts of interest.

\section{References}

[1] Tsur, R. (1992) Toward a Theory of Cognitive Poetics. North Holland, Amsterdam.

[2] Stockwell, P. (2002) Cognitive Poetics: An Introduction. Routledge, London.

[3] Liu, C. (2019) The Cognitive Interpretation of Saying Good-bye to Cambridge Again from the Perspective of Graphic Background Theory. Journal of Jiangxi Electric Power Vocational and Technical College, 32, 138-139.

[4] Talmy, L. (2000) Toward a Cognitive Semantics (Vol. 1). The MIT Press, Cambridge.

[5] Cao, F. (2013) Analysis of English Compound Sentences from a Graphic-Contextual Perspective. Anhui University, Hefei.

[6] Sun, W. and Wen, X. (2011) On the Classical Rhythm of the Imagery of Xu Zhimo's Saying Good-Bye to Cambridge Again. Language Teaching Newsletter, 12, 96-98. 